\title{
Feasibility and comparison of left ventricular ejection flow acceleration recorded by cardiac magnetic resonance in patients with dilated cardiomyopathy: a case-control study
}

\author{
Sébastian Tavolaro ${ }^{1,2}$ \\ From 18th Annual SCMR Scientific Sessions \\ Nice, France. 4-7 February 2015
}

\section{Background}

Intra-ventricular pressure gradient along the direction of the outflow tract is generated by the impulse response of the myocardial contraction. This spatial pressure gradient, derived from the maximal acceleration estimates within flow along the left ventricular out flow tract (LVOT), has been validated in vitro by using MRI and was found strongly related to the inotropic state of the LV as demonstrated in animal and human echocardiographic studies. This acceleration may be less dependent on load conditions than others LV systolic function parameters, especially LV ejection fraction (LVEF). The aim of this study was to evaluate the feasibility of LV ejection flow acceleration estimated by spatial and temporal derivative of velocities recorded by cardiac magnetic resonance (CMR) using phase contrast sequence, and to compare the acceleration values to LVEF in patients with dilated cardiomyopathy (DCM) and in control subjects.

\section{Methods}

Fourteen DCM patients and fourteen controls (mean age: 56 vs. 33 years old respectively) underwent CMR. Through plane phase contrast acquisitions were obtained in breathhold at the level of aortic valve and $10 \mathrm{~mm}$ below through the LVOT. Total acceleration (TotalAcc) and its two components, Temporal (TempAcc) and Convective (ConvAcc) acceleration were estimated from velocities derived with time and space obtained at the two different levels by using our home-

${ }^{1}$ Radiology, European Hospital Georges Pompidou, Paris, France Full list of author information is available at the end of the article made previously validated semi-automatic software ArtFUN.

\section{Results}

Acceleration measurement was feasible in all controls and in fourteen out of seventeen patients $(82 \%)$. TotalAcc and TempAcc $\left(R^{2}=0.45, p<0.0001\right.$ and $R^{2}=0.49$, $\mathrm{p}<0.0001$ respectively) but not ConvAcc $\left(\mathrm{R}^{2}=0.004\right.$, $\mathrm{p}=0.74$ ) were correlated with LVEF. Compared to control, mean LVEF $(25 \pm 9$ vs. $66 \pm 5, \mathrm{p}<0.0001)$ TotalAcc $\left(1097 \pm 317\right.$ vs. $\left.1818 \pm 306 \mathrm{~cm} \cdot \mathrm{s}^{-2}, \mathrm{p}<0.0001\right)$ and TempAcc $\left(1066 \pm 272\right.$ vs. $\left.1656 \pm 257 \mathrm{~cm} . \mathrm{s}^{-2,} \mathrm{p}<0.0001\right)$ but not ConvAcc $\left(706 \pm 478\right.$ vs. $\left.840 \pm 613 \mathrm{~cm} \cdot \mathrm{s}^{-2}, \mathrm{p}=0.743\right)$ were significantly lower in DCM.

\section{Conclusions}

This preliminary study have shown the feasibility of LV ejection flow acceleration measurement derived from velocities obtained 2 breatholding by using phase contrast sequence in CMR at two level perpendicular to the LVOT. TotalAcc and TempAcc are significantly lower in DCM patients compared to controls. TempAcc is correlated to LVEF, better than TotalAcc.

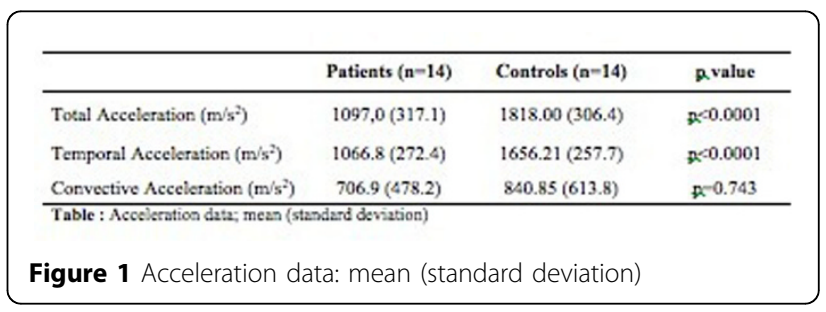




\begin{tabular}{|c|c|c|}
\hline & $\mathrm{R}^{2}$ & Rvalue \\
\hline \multicolumn{3}{|l|}{ LVEF } \\
\hline Total Acceleration & 0.45 & $x=0.0001$ \\
\hline Temporal Acceleration & 0.49 & $x<0.0001$ \\
\hline Convective Acceleration & 0.0004 & $p=0.74$ \\
\hline \multicolumn{3}{|l|}{ Cardiac output } \\
\hline Total Acceleration & 0.27 & no -0.0027 \\
\hline Temporal Acceleration & 0.26 & מn- -0.0036 \\
\hline Convoctive Acceleration & 0.02 & D- -0.75 \\
\hline \multicolumn{3}{|l|}{ LV remodeling } \\
\hline Total Acceleration & 0.18 & Dh 0.024 \\
\hline Temporal Acceleration & 0.22 & Dh 0.010 \\
\hline Convoctive Acceleration & 0.0007 & $\mathrm{p}-0.88$ \\
\hline
\end{tabular}

Figure 2 Univariate analysis correlations summary.

\section{Funding}

N/A.

\section{Authors' details}

${ }^{1}$ Radiology, European Hospital Georges Pompidou, Paris, France. ${ }^{2}$ INSERM,

Paris, France.

Published: 3 February 2015

doi:10.1186/1532-429X-17-S1-P63

Cite this article as: Tavolaro: Feasibility and comparison of left

ventricular ejection flow acceleration recorded by cardiac magnetic

resonance in patients with dilated cardiomyopathy: a case-control

study. Journal of Cardiovascular Magnetic Resonance 2015 17(Suppl 1):P63.

Submit your next manuscript to BioMed Central and take full advantage of:

- Convenient online submission

- Thorough peer review

- No space constraints or color figure charges

- Immediate publication on acceptance

- Inclusion in PubMed, CAS, Scopus and Google Scholar

- Research which is freely available for redistribution

Submit your manuscript at www.biomedcentral.com/submit
C Biomed Central 